Check for updates

Cite this: Nanoscale Adv., 2019, 1, 265

\title{
Electrochemically assisted flexible lanthanide upconversion luminescence sensing of heavy metal contamination with high sensitivity and selectivity $\dagger$
}

\author{
Yuen-Ting Wong, \$ Sin-Yi Pang, \$ Ming-Kiu Tsang, (D) Yan Liu, Haitao Huang, \\ Siu-Fung Yu (D) and Jianhua Hao (D)*
}

\begin{abstract}
Heavy metal contamination in water can pose lethal threats to public health; therefore it is highly desired to develop a rapid and sensitive sensor for monitoring water quality. Owing to their superior optical features, upconversion nanoparticles (UCNPs) are widely explored to detect metal ions based on resonance energy transfer to dye quenchers. However, these schemes heavily rely on the optical properties of the molecules, which limits the flexibility of the probe design. Herein, a flexible carbon fiber cloth/UCNP composite probe was fabricated for sensing copper(II) $\left(\mathrm{Cu}^{2+}\right)$ ions and an electrochemical (E-chem) technique was implemented for the first time to enhance its sensing performance. By applying $0.3 \mathrm{~V}$ on the composite probe, $\mathrm{Cu}^{2+}$ ions can be effectively accumulated through oxidation, yielding a remarkable improvement in the selectivity and sensitivity. A more outstanding detection limit of the sensor was achieved at $82 \mathrm{ppb}$ under the E-chem assistance, with 300-fold enhancement compared to the detection without the E-chem effect. This sensing approach can be an alternative to molecular quenchers and open up new possibilities for simple, rapid and portable sensing of metal ions.
\end{abstract}

Received 6th June 2018

Accepted 4th July 2018

DOI: $10.1039 / c 8 n a 00012 c$

rsc.li/nanoscale-advances absence of autofluorescence for an improved signal-to-noise ratio. ${ }^{6}$ In addition, their excellent photo-stability and biocompatibility make these nanophosphors vital in biosensing $^{7-9}$ and bioimaging. ${ }^{10-13}$

Numerous reports have revealed the good sensitivity and selectivity of UCL sensors towards various metal ions such as $\mathrm{Zn}^{2+},{ }^{8} \mathrm{Cu}^{2+},{ }^{14-16} \mathrm{Hg}^{2+},{ }^{17}$ and $\mathrm{Pb}^{2+}$ ions. ${ }^{18}$ Most strategies were established based on the luminescence resonance energy transfer (LRET) phenomenon, by which metal-responsive dyes played important roles in quenching UCL for ratiometric luminescence sensing while promoting the selectivity. However, these sensors rely heavily on the optical properties, conjugation efficiency and stability of molecules. In particular, absorption bands of the quenchers must overlap with upconversion emissions of the UCNPs to realize effective LRET. It should be noted that energy gap modulation for molecular quenchers can be challenging and this may limit the flexibility of the sensor design. ${ }^{19}$ Another barrier is to functionalize organic molecules, which allows chemical conjugation onto UCNPs to enhance conjugation efficiency and minimize leakage. In spite of improved optical responses and stability, the functionalization may complicate the design and synthesis of dyes. This paves an attractive way to establish an UCL sensor without using molecular quenchers or chelating agents.

Heavy metal ions have a pronounced quenching effect on emissions from lanthanide ions through efficient electron transfer. ${ }^{19-21} \mathrm{~A}$ recent study has revealed that $\mathrm{Cu}^{2+}$ ions could quench $95 \%$ of the UCL of $N, N$-di(2-picolyl)ethylenediamine
Department of Applied Physics, The Hong Kong Polytechnic University, Hung Hom, Kowloon, Hong Kong, China. E-mail: jh.hao@polyu.edu.hk

$\dagger$ Electronic supplementary information (ESI) available. See DOI: 10.1039/c8na00012c

\$ Y.-T. Wong and S.-Y. Pang contributed equally to this work. 
(DPEA)-modified $\mathrm{NaYF}_{4} @ \mathrm{NaYF}_{4}: \mathrm{Yb}, \mathrm{Tm}_{\mathrm{N}} @ \mathrm{NaYF}_{4} \mathrm{UCNPs}$ without involving the LRET process. ${ }^{19}$ Although the concept of heavy metal ion-induced deactivation has been successfully employed to monitor biothiols in living tissues, it still required DPEA molecules to anchor $\mathrm{Cu}^{2+}$ ions on the probe surface. Considering that the lack of metal-chelating molecules deteriorates the UCL sensing performance,$^{\mathbf{2 0}}$ the choice of phosphors and other techniques becomes critical to overcome this limitation. $\mathrm{NaGdF}_{4}: \mathrm{Yb} / \mathrm{Tm} @ \mathrm{NaGdF}_{4}: \mathrm{Eu}$ core@shell UCNPs are a potential candidate for sensing $\mathrm{Cu}^{2+}$ ions. On the one hand, the characteristic red emissions of $\mathrm{Eu}^{3+}$ ions can be effectively deactivated by $\mathrm{Cu}^{2+}$ ions via electron transfer or/and LRET to intensify optical responses. A thin layer of a $\mathrm{Eu}^{3+}$-silica downconverting matrix was utilized for $\mathrm{Cu}^{2+}$ ion sensing with detection limit down to 50 ppb. ${ }^{21}$ On the other hand, a $\mathrm{Gd}^{3+}$-doped host is not only able to promote the hexagonal crystal phase, ${ }^{22}$ but also allow an energy migration-mediated (EMU) mechanism to achieve the most efficient UCL of $\mathrm{Eu}^{3+}$ ions. ${ }^{23}$

Porous composite materials have drawn much attention because the pores provide large loading capacity and surface area as reaction sites, ${ }^{\mathbf{2 4 - 2 6}}$ while a composite exhibits multifunctional properties for widespread applications. ${ }^{27,28}$ More importantly, inspired by the outstanding selectivity of electrochemical (E-chem) sensors, ${ }^{29}$ we introduced an E-chem technique for UCL probes for the sake of better $\mathrm{Cu}^{2+}$ ion accumulation on the probes via redox reactions. Therefore, the sensing performance can be improved as illustrated in Fig. 1. As a proof of concept, a composite probe was fabricated by electrostatic adsorption of core@shell UCNPs onto a flexible carbon fiber cloth (CFC), denoted as CFC-UCNP probe. CFC is extensively utilized in energy storage applications because of its low cost, good mechanical properties, chemical stability and electrical conductivity. ${ }^{30,31}$ Furthermore, its porous structure offers large surface area for accommodating the nanophosphors and supporting E-chem reactions, which make CFCs attractive as an E-chem-assisted UCL sensing platform. It should be mentioned that the feature of low energy excitation in a UCL sensor can avoid background interference from the ultraviolet absorption of carbon-based electrodes. In addition to its multi-functional properties, the excellent flexibility and easy processability of

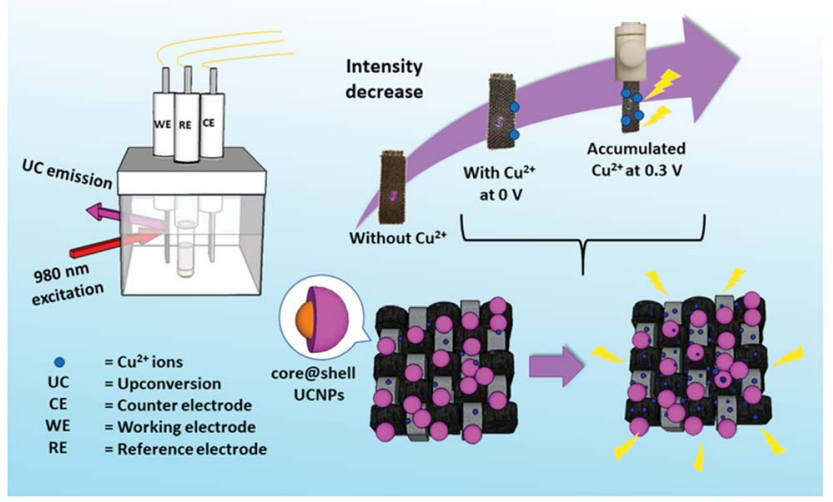

Fig. 1 A schematic diagram showing the CFC-UCNP probe for $\mathrm{Cu}^{2+}$ ion sensing under the E-chem assistance. the composite probe enable easily handled fabrication and sensing applications. ${ }^{28}$

The sensitivity and selectivity of the CFC-UCNP probe were greatly improved after applying a low oxidation potential of $0.3 \mathrm{~V}$. Notably, its limit of detection (LOD) was drastically lowered from $25.8 \mathrm{ppm}$ to $82 \mathrm{ppb}$. To the best of our knowledge, this is the first time that an E-chem technique has been introduced to improve UCL sensing of $\mathrm{Cu}^{2+}$ ions. It is noteworthy that the LOD of this sensing approach is lower than the tolerance levels of $2 \mathrm{ppm}$ and $1.3 \mathrm{ppm}$ suggested by the World Health Organization (WHO) ${ }^{32}$ and the United States Environmental Protection Agency (USEPA), ${ }^{33}$ respectively. Therefore, this proposed E-chem-assisted sensing by flexible CFC-UCNP probes has potential for rapid and portable sensing of $\mathrm{Cu}^{2+}$ ions in drinking water. Moreover, it can be possibly extended for sensing other heavy metal ions by using an appropriate applied voltage and electrolyte.

\section{Materials and methods}

\section{Materials}

Gadolinium(III) acetate hydrate $\left(\mathrm{Gd}\left(\mathrm{CH}_{3} \mathrm{CO}_{2}\right)_{3} \cdot x \mathrm{H}_{2} \mathrm{O}, 99.9 \%\right)$, ytterbium(III) acetate hydrate $\left(\mathrm{Yb}\left(\mathrm{CH}_{3} \mathrm{CO}_{2}\right)_{3} \cdot 4 \mathrm{H}_{2} \mathrm{O}, 99.95 \%\right)$, thulium(III) acetate hydrate $\left(\mathrm{Tm}\left(\mathrm{CH}_{3} \mathrm{CO}_{2}\right)_{3} \cdot x \mathrm{H}_{2} \mathrm{O}, 99.9 \%\right)$, europium(III) acetate hydrate $\left(\mathrm{Eu}\left(\mathrm{CH}_{3} \mathrm{CO}_{2}\right)_{3} \cdot x \mathrm{H}_{2} \mathrm{O}, 99.9 \%\right)$, sodium hydroxide pellets $(\mathrm{NaOH}, 98 \%)$, ammonium fluoride $\left(\mathrm{NH}_{4} \mathrm{~F}, 99.99 \%\right)$, 1-octadecene (1-ODE, 90\%), oleic acid (OA, 90\%), methanol (99.8\%), anhydrous ethanol (EtOH), acetone (99.9\%), cyclohexane (99.5\%), hydrochloric acid ( $\mathrm{HCl}, 37 \%)$ and nitric acid $\left(\mathrm{HNO}_{3}, 70 \%\right)$, sodium chloride ( $\left.\mathrm{NaCl}, 99 \%\right)$, copper(II) sulfate $\left(\mathrm{CuSO}_{4}, 99.99 \%\right)$, cobalt(II) sulphate heptahydrate $\left(\mathrm{CoSO}_{4} \cdot 7 \mathrm{H}_{2} \mathrm{O}, 99 \%\right)$, nickel(II) sulphate hexahydrate $\left(\mathrm{NiSO}_{4}{ }^{-}\right.$ $\left.\cdot 6 \mathrm{H}_{2} \mathrm{O}, 98 \%\right)$, calcium(II) chloride $\left(\mathrm{CaCl}_{2}, 96 \%\right)$, barium(II) chloride $\left(\mathrm{BaCl}_{2}, 99.9 \%\right)$, zinc(II) nitrate hexahydrate $\left(\mathrm{Zn}\left(\mathrm{NO}_{3}\right)_{2}\right.$ $\left.\cdot 6 \mathrm{H}_{2} \mathrm{O}, 98 \%\right)$, lead(II) nitrate $\left(\mathrm{Pb}\left(\mathrm{NO}_{3}\right)_{2}, 99 \%\right)$, iron(III) nitrate nonahydrate $\left(\mathrm{Fe}\left(\mathrm{NO}_{3}\right)_{3} \cdot 9 \mathrm{H}_{2} \mathrm{O}, 98 \%\right)$, chromium(III) nitrate nonahydrate $\left(\mathrm{Cr}\left(\mathrm{NO}_{3}\right)_{3} \cdot 9 \mathrm{H}_{2} \mathrm{O}, 99.99 \%\right)$, and manganese(II) acetate tetrahydrate $\left(\mathrm{Mn}\left(\mathrm{CH}_{3} \mathrm{CO}_{2}\right)_{2} \cdot 4 \mathrm{H}_{2} \mathrm{O}, \quad 99 \%\right)$ were purchased from Sigma-Aldrich. CFCs were purchased from CeTech (W0S1002). All materials were used without further purification unless mentioned specifically.

\section{Synthesis of $\mathrm{NaGdF}_{4}: 49 \% \mathrm{Yb}: 1 \%$ Tm core UCNPs}

The OA-capped UCNPs were synthesised by the co-precipitation route. ${ }^{34} 0.2 \mathrm{M}$ aqueous solutions of $\mathrm{Ln}\left(\mathrm{CH}_{3} \mathrm{CO}_{2}\right)_{3}(\mathrm{Ln}=\mathrm{Gd}$, $\mathrm{Yb}$ and $\mathrm{Tm}$ ) were mixed with $4 \mathrm{~mL}$ OA and $6 \mathrm{~mL}$ 1-ODE in a twonecked flask. The mixture was heated at $150{ }^{\circ} \mathrm{C}$ for $40 \mathrm{~min}$ under vigorous magnetic stirring. After cooling the solution to $50{ }^{\circ} \mathrm{C}$, a methanolic mixture of $\mathrm{NH}_{4} \mathrm{~F}(1.3 \mathrm{mmol})$ and $\mathrm{NaOH}$ ( $1 \mathrm{mmol}$ ) was quickly added and heated at $50{ }^{\circ} \mathrm{C}$ for $1 \mathrm{~h}$. The temperature was then increased to $100{ }^{\circ} \mathrm{C}$ to remove the methanol residue and the colloidal solution was finally heated to $290{ }^{\circ} \mathrm{C}$ under argon protection for $90 \mathrm{~min}$. The core UCNPs were collected by centrifugation and washed with EtOH several times. They were dispersed in cyclohexane for further use. 


\section{Synthesis of $\mathrm{NaGdF}_{4}: 49 \% \mathrm{Yb}: 1 \% \mathrm{Tm} @ \mathrm{NaGdF}_{4}: 15 \% \mathrm{Eu}$ core@shell UCNPs}

The growth of the Eu-doped shell on the core UCNPs was achieved by a route similar to the one above. ${ }^{34}$ Briefly, $0.2 \mathrm{M}$ aqueous solutions of $\mathrm{Ln}\left(\mathrm{CH}_{3} \mathrm{CO}_{2}\right)(\mathrm{Ln}=\mathrm{Gd}$ and $\mathrm{Eu})$ were heated with $4 \mathrm{~mL} \mathrm{OA}$ and $6 \mathrm{~mL} 1-\mathrm{ODE}$ at $150{ }^{\circ} \mathrm{C}$ for $40 \mathrm{~min}$. The core UCNPs dispersed in cyclohexane were added to the mixture under stirring at $50{ }^{\circ} \mathrm{C}$. Subsequently, a methanolic mixture containing $\mathrm{NH}_{4} \mathrm{~F}$ and $\mathrm{NaOH}$ was quickly added. The colloidal solution was maintained at $50^{\circ} \mathrm{C}$ for $1 \mathrm{~h}$ and then degassed by raising the temperature to $100{ }^{\circ} \mathrm{C}$. After heating the colloidal solution at $290{ }^{\circ} \mathrm{C}$ for $90 \mathrm{~min}$ with argon gas purging, the core@shell nanoparticles were collected by centrifugation, followed by washing with EtOH several times and re-dispersion in cyclohexane for further use.

\section{Preparation of ligand free core@shell UCNPs}

The OA ligands of core@shell UCNPs were removed by a modified acid treatment. ${ }^{35}$ Briefly, core@shell UCNPs were firstly dispersed in aqueous solution, whose $\mathrm{pH}$ was tuned to 4 by adding $0.1 \mathrm{M} \mathrm{HCl}$. After stirring for $2 \mathrm{~h}$, cyclohexane was added to the colloidal solution, followed by ultra-sonication and oil extraction for a few times to remove free OA. The colloidal solution was centrifuged at $13000 \mathrm{rpm}$ for $40 \mathrm{~min}$ and purified by repeated washing with EtOH and D.I. water.

\section{Fabrication of the CFC-UCNP probe}

The CFCs were oxidized by concentrated $\mathrm{HNO}_{3}$ to induce negative surface charges for more efficient electrostatic adsorption of the nanophosphors. ${ }^{36}$ Simply, the organic impurities on the CFC surface were removed by ultra-sonication with acetone and EtOH. Then, the dried CFCs were refluxed in $10 \mathrm{~mL}$ concentrated $\mathrm{HNO}_{3}$ at $100{ }^{\circ} \mathrm{C}$ for $5 \mathrm{~h}$. The CFCs were finally washed with D.I. water several times to remove any acid residues. To conjugate ligand free core@shell UCNPs on an acidtreated CFC, the cloth $(0.5 \mathrm{~cm} \times 2 \mathrm{~cm})$ was immersed in $40 \mathrm{mg} \mathrm{mL} \mathrm{m}^{-1}$ of the prepared UCNPs with shaking for $6 \mathrm{~h}$, followed by repeated washing with deionized (D.I.) water, ultrasonication and air-drying.

\section{Characterization}

A JEOL-2100F transmission electron microscope (TEM) equipped with an Oxford Instruments energy dispersive X-ray (EDX) system was operated at $200 \mathrm{kV}$ to characterize the morphology of the UCNPs. The crystal structure of the core@shell UCNPs was also characterized by high resolution transmission electron microscopy (HRTEM) and selected area electron diffraction (SAED). The samples used in TEM were prepared on holey carbon coated 400 mesh copper grids. Powder X-ray diffraction (XRD) patterns were recorded to confirm the crystal structure of the UCNPs using a Rigaku SmartLab 9 kW (Rigaku, Japan) using $\mathrm{Cu} \mathrm{K} \alpha$ radiation $(\lambda=0.15406 \mathrm{~nm})$. The surface properties of the UCNPs were studied by using a PerkinElmer Spectrum 100 Fourier-transform infrared spectroscopy (FTIR) spectrometer (PerkinElmer Inc., USA) equipped with a deuterated triglycine sulphate detector and $\mathrm{KBr}$ beam splitter assembly. UCL spectra were recorded and lifetime measurements performed using an FLS920 (Edinburgh Instruments) equipped with a continuous wave $980 \mathrm{~nm}$ diode laser excitation source and pulsed laser modulator. An external voltage DC source (JC1803A) purchased from Hang Zhou Jingce Electronics Co., Ltd was used for the photoluminescence experiments, which were conducted in $1 \mathrm{M}$ $\mathrm{NaCl}$ electrolyte unless mentioned specifically. Cyclic voltammetry (CV) experiments were performed using a Solartron Analytical 1400 cell test system connected to a standard threeelectrode system in $1 \mathrm{M} \mathrm{NaCl}$ electrolyte, which contained the as-prepared CFC-UCNP probe as the working electrode, a $1 \times$ $1 \mathrm{~cm}^{2}$ platinum plate as the counter electrode and a saturated calomel reference electrode.

\section{Results and discussion}

\section{Characterization of the UCNPs and CFC-UCNP probe}

All crystalline OA-capped UCNPs were synthesized via a coprecipitation route. ${ }^{34}$ The TEM images (Fig. S1†) indicate that the as-prepared UCNPs were mono-disperse. The epitaxial growth of the $\mathrm{Eu}^{3+}$-doped shell changed the shape of the nanophosphors from spherical to hexagonal, associated with an average size increase by $8.92 \mathrm{~nm}$ to yield $43.8 \mathrm{~nm}$ core@shell UCNPs. The XRD patterns (Fig. S2 $\dagger$ ) of the as-prepared UCNPs are in accord with the standard pattern of hexagonal $\mathrm{NaGdF}_{4}$ crystals (JCPDS\#27-0699), suggesting the absence of phase change in the crystals after shell growth. In addition, the lattice spacing of $5.2 \AA$ in the HRTEM image of the core@shell UCNPs (Fig. 2a) was indexed to the (100) plane of hexagonal $\mathrm{NaGdF}_{4}$ crystals. These structural characterization results are consistent with the SAED pattern of the core@shell UCNPs (Fig. 2b), further confirming their hexagonal crystal phase. Acid treatment played a role in removing OA surface ligands to endow the core@shell UCNPs with good water dispersibility and positive surface charges. ${ }^{35}$ Their naked surface is verified by the disappearance of infrared absorption peaks at around $2900 \mathrm{~cm}^{-1}$ and $1500 \mathrm{~cm}^{-1}$, characteristic of $\mathrm{C}-\mathrm{H}$ and -COO stretching vibrations, respectively (Fig. S3 $\dagger$ ). Moreover, a broad band centered at $3435 \mathrm{~cm}^{-1}$, corresponding to $-\mathrm{OH}$ vibration, becomes more obvious for the ligand free core@shell UCNPs.

The OA-capped core@shell UCNPs exhibited strong purple UCL upon $980 \mathrm{~nm}$ excitation, with the appearance of new emission peaks at 578, 591, 615 and $690 \mathrm{~nm}$ compared to the blue-emitting core UCNPs (Fig. $\mathrm{S} 4 \mathrm{a}$ and $\mathrm{b} \dagger$ ). These peaks are the characteristic UCL of $\mathrm{Eu}^{3+}$ ions responsible for the transitions of ${ }^{5} \mathrm{D}_{1} \rightarrow{ }^{7} \mathrm{~F}_{3}$ and ${ }^{5} \mathrm{D}_{0} \rightarrow{ }^{7} \mathrm{~F}_{J}\left(J=1,2\right.$ and 4 respectively) ${ }^{23}$ Fig. S4c $\dagger$ depicts the EMU mechanism of the core@shell UCNPs. Briefly, $980 \mathrm{~nm}$ photons sensitized by $\mathrm{Yb}^{3+}$ ions are accumulated in the ${ }^{1} \mathrm{I}_{6}$ excited state of $\mathrm{Tm}^{3+}$ ions via successive $\mathrm{Yb}^{3+}-\mathrm{Tm}^{3+}$ energy transfer. The energy is bridged to $\mathrm{Eu}^{3+}$ ions in the shell layer by the high-lying ${ }^{6} \mathrm{P}_{7 / 2}$ state in $\mathrm{Gd}^{3+}$ ions which gives rise to the red emissions. It is worth noting that -OH surface quenchers on the naked nanophosphors greatly weakened the UCL at $615 \mathrm{~nm}$ by 1.6-fold compared to OA-capped nanophosphors (Fig. 2e). ${ }^{35}$ These optical observations prove the successful preparation of ligand free core@shell UCNPs, and are consistent with the 


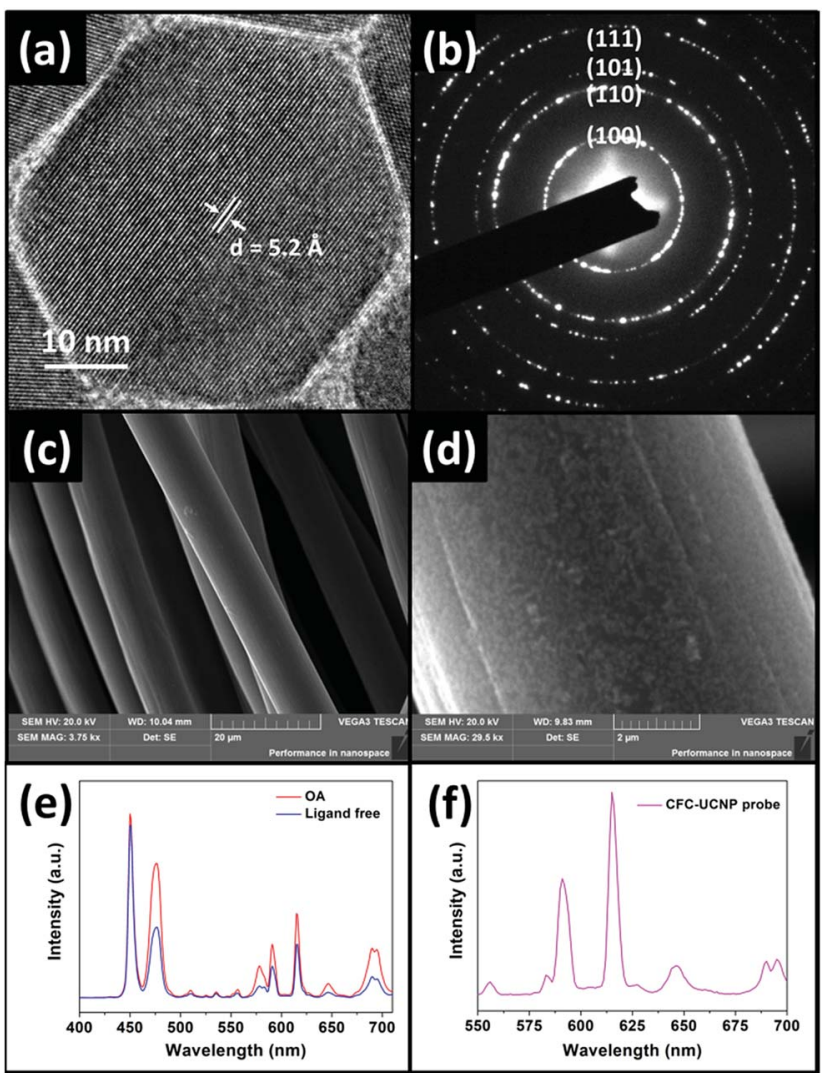

Fig. 2 (a) HRTEM and (b) SAED images of the coreashell UCNPS. SEM images of (c) CFC and (d) the CFC-UCNP probe. UCL spectra of (e) OA-capped and ligand free coreashell UCNPs and (f) the CFC-UCNP probe under $980 \mathrm{~nm}$ excitation.

aforementioned FTIR characterization. The CFC-UCNP probe was fabricated by $6 \mathrm{~h}$ electrostatic adsorption of the ligand free nanophosphors onto an acid-treated CFC (Fig. S5a†). Notably, the characteristic purple UCL of $\mathrm{Tm}^{3+} / \mathrm{Eu}^{3+}$ ions on the CFCUCNP probe could be observed by the naked eye under $980 \mathrm{~nm}$ laser irradiation, while two major UCL peaks of the composite probe at 591 and $615 \mathrm{~nm}$ are not altered (Fig. 2f). By comparing the $615 \mathrm{~nm}$ emission of the initial and residual core@shell UCNPs used for the adsorption process, about $1.5 \mathrm{mg}$ of them was accommodated into the cloth (Fig. S5b†). The increased roughness on carbon fibers observed in the SEM images (Fig. 2c and d and S6a-d $\mathrm{d}$ ) results from the substantial attachment of spot-like core@shell UCNPs. Furthermore, the EDX spectra (Fig. S6e and $f_{\dagger}^{\dagger}$ ) evidence the presence of the constituent elements of core@shell UCNPs in the CFC-UCNP probe but not in the CFC.

\section{UCL sensing without E-chem assistance}

$\mathrm{NaCl}$ (aq.) serves as an electrolyte necessary for E-chem reactions and chloride ions are able to stabilize $\mathrm{Cu}^{2+}$ ions in the form of copper(I) $\left(\mathrm{Cu}^{+}\right)$chloride complexes. ${ }^{37}$ This is evidenced by a red shifted absorption band of $\mathrm{CuSO}_{4}$ in concentrated $\mathrm{NaCl}$ (aq.), together with a color change from blue to green (Fig. S7a †). Since the absorption bands of $\mathrm{Cu}^{+}$and $\mathrm{Cu}^{2+}$ ions overlap with the 615 and $690 \mathrm{~nm}$ emissions of $\mathrm{Eu}^{3+}$ ions, LRET possibly takes place once the metal ions are in close proximity to the core@shell UCNPs. As a result, UCL deactivation for the metal ion sensing can be achieved by electron transfer and LRET processes.

UCL sensing assays supported on a porous substrate can improve the sensitivity and selectivity. ${ }^{26}$ As a proof of concept, $\mathrm{Cu}^{2+}$ ion sensing was firstly studied with ligand free core@shell UCNPs in D.I. water and $1 \mathrm{M} \mathrm{NaCl}$ (aq.), respectively (Fig. S8†). Unfortunately, optical sensing could not be effectively accomplished because UCL is very susceptible to an environment with high ionic strength and various surface quenchers. ${ }^{35}$ In contrast to solution-based sensing, emission of the CFC-UCNP probe at $615 \mathrm{~nm}$ was expectedly quenched with increasing $\mathrm{Cu}^{2+}$ ions (Fig. 3a). Therefore, the porous structure of CFC not only protects the nanophosphors from a complicated environment, but also likely concentrates them to enhance the optical responses.

The UCL quenching of the CFC-UCNP probe was evaluated using the Stern-Volmer (SV) relationship: $:^{19-21}$

$$
\frac{I_{\mathrm{o}}-I}{I}=K_{\mathrm{SV}}[\mathrm{Q}]
$$

where $I_{\mathrm{o}}$ and $I$ are the emission intensity before and after adding $\mathrm{Cu}^{2+}$ ions, respectively, $K_{\mathrm{SV}}$ is the $\mathrm{SV}$ constant and $[\mathrm{Q}]$ is the quencher concentration. The resulting negative deviation from linearity (Fig. S9a $\dagger$ ) is the feature of mixed dynamic and static quenching processes caused by the heterogeneity in a system. ${ }^{21}$ The heterogeneity can be further elucidated by the co-existence of surface and inner phosphors which are exposed to metal ion quenchers at unequal probabilities and quenching constants. The quenching mechanism in a hybrid system can be described by a modified SV relationship: ${ }^{21}$
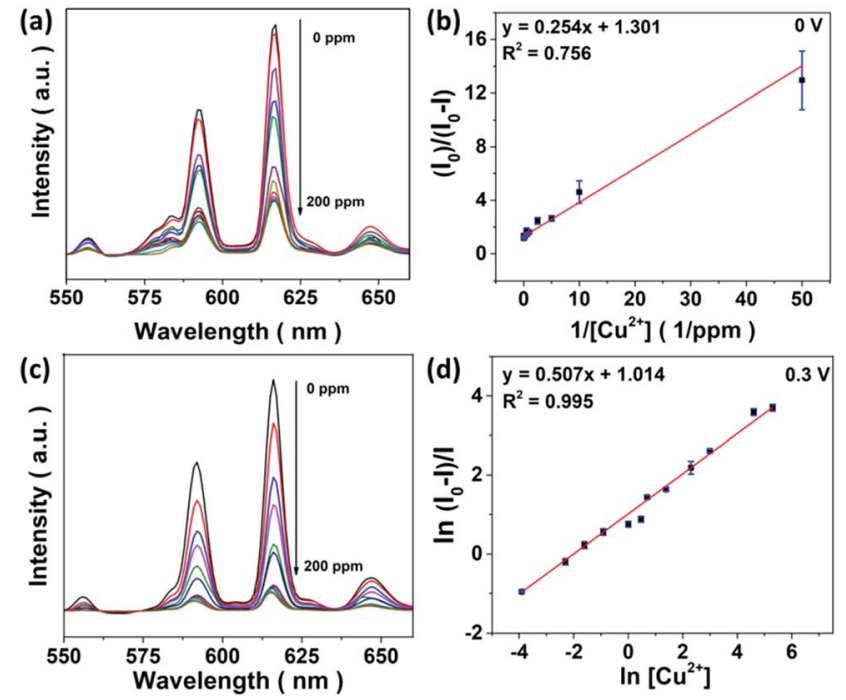

Fig. 3 (a) UCL spectra of the CFC-UCNP probe for sensing 0$200 \mathrm{ppm} \mathrm{Cu}{ }^{2+}$ ions at $\mathrm{O} \mathrm{V}$ and (b) the corresponding linear relationship at $615 \mathrm{~nm}$ emission based on the modified SV equation. (c) UCL spectra of the CFC-UCNP probe for sensing 0-200 ppm Cu${ }^{2+}$ ions at $0.3 \mathrm{~V}$ and $(\mathrm{d})$ the corresponding linear relationship at $615 \mathrm{~nm}$ emission based on the double natural logarithm SV equation. Io and / refer to the $\mathrm{UCL}$ intensity before and after adding $\mathrm{Cu}^{2+}$ ions, respectively. 


$$
\frac{I_{\mathrm{o}}}{I_{\mathrm{o}}-I}=\frac{1}{f_{\mathrm{a}}}+\frac{1}{f_{\mathrm{a}} K_{\mathrm{SV}}} \frac{1}{[\mathrm{Q}]}
$$

where $f_{\mathrm{a}}$ is the factor of quenchable sites. An excellent linearity was obtained for $\mathrm{Cu}^{2+}$ ion sensing (Fig. S9c $\dagger$ ) but it could not be maintained well from replicate measurements (Fig. 3b). It reveals that the composite probe lacks stability for optical sensing at $0 \mathrm{~V}$, resulting in inferior sensitivity associated with a large LOD at $25.8 \mathrm{ppm}$. The findings may underline the importance of the metal-chelating molecules or any driving forces to shorten the distance between the nanophosphors and analyte ions for effective deactivation.

\section{E-chem performance and voltage effects on the CFC-UCNP probe}

The E-chem performance of the CFC-UCNP probe was studied in order to evaluate if the proposed E-chem-assisted sensing approach is feasible. Fig. 4a illustrates the working principle of a typical E-chem sensor utilizing the composite probe as a working electrode. It provides a platform to support redox reactions of analyte ions at given voltages and produce various currents. These processes can be simply presented as $\mathrm{Cu}^{+}$(ads.) $\rightleftharpoons \mathrm{Cu}^{2+}$ (ads.) $+\mathrm{e}^{-}$for oxidation and reversed for reduction. Cyclic voltammetry $(\mathrm{CV})$ is a traditional and reliable technique that can be used to detect these current signals by applying a range of voltages cyclically to the system. Hence, the current signals across the CFC-UCNP probe were measured in the potential window of $0-0.5 \mathrm{~V}$ at a scan rate of $100 \mathrm{mV} \mathrm{s}^{-1}$. The nearly identical CV curves of the CFC and CFC-UCNP electrodes (Fig. S10†) revealed the electrochemically inert nature of the nanophosphors at low potentials, which is beneficial for obtaining E-chem responses only from the analyte ions. After mixing different aliquots of $\mathrm{CuSO}_{4}$ (aq.) with the electrolyte, redox peaks appeared at around $0.3 \mathrm{~V}$ (forward bias) and $0.2 \mathrm{~V}$ (reverse bias) (Fig. 4b). They are ascribed to the oxidation of $\mathrm{Cu}^{+}$ ions and reduction of $\mathrm{Cu}^{2+}$ ions, respectively. ${ }^{38}$ Positive linear relationships between the current density and $\left[\mathrm{Cu}^{2+}\right]$ were individually obtained from $0.3 \mathrm{~V}$ (Fig. 4c) and $0.2 \mathrm{~V}$ (Fig. S11 $\dagger$ ). Based on the $3 \sigma /$ slope rule, ${ }^{39}$ their LODs were estimated at $125 \mathrm{ppb}$ and $132 \mathrm{ppb}$, respectively.

Encouraged by the effective oxidation of $\mathrm{Cu}^{+}$ions on the cloth, voltage effects on UCL at $615 \mathrm{~nm}$ of the composite probe were examined. It was found that low anodic potential could induce UCL deactivation (Fig. S12a †) along with a shortened lifetime from 5.07 to $4.88 \mathrm{~ms}$ (Fig. S12b $\dagger$ ) because of high susceptibility of UCL to the applied electricfield. ${ }^{40}$ Notably, voltages beyond $0.2 \mathrm{~V}$ fostered a steady quenching effect on the red emission and $0.3 \mathrm{~V}$ triggered UCL fluctuation as slight as $0 \mathrm{~V}$ in the time-lapse experiments (Fig. S12c and $\mathrm{d} \dagger$ ). The nanophosphors are less likely to detach from the CFC in the electrolyte, so the low anodic potential at $0.3 \mathrm{~V}$ poses a small effect on the composite probe for the optical sensing.

(a)
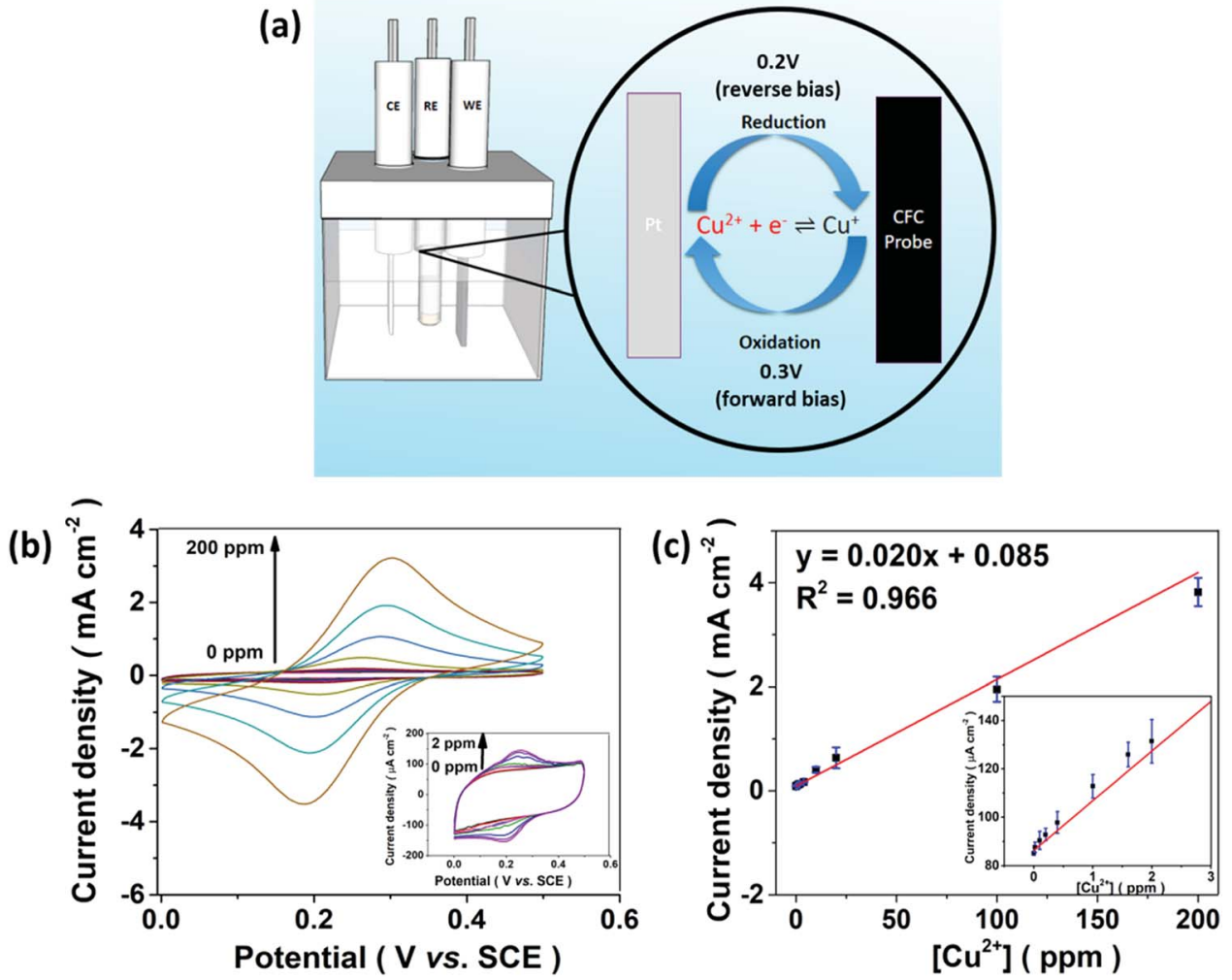

Fig. 4 (a) A diagram illustrating the E-chem processes on the CFC-UCNP probe. (b) CV curves of the CFC-UCNP probe in response to 0$200 \mathrm{ppm} \mathrm{Cu}{ }^{2+}$ ions recorded within the potential window of $0-0.5 \mathrm{~V}$ at $100 \mathrm{mV} \mathrm{s}^{-1}$. (c) The linear relationship between the E-chem signals and $\left[\mathrm{Cu}^{2+}\right]$ obtained at $0.3 \mathrm{~V}$. The insets are the enlarged plots for $0-2 \mathrm{ppm} \mathrm{Cu}^{2+}$ ions. 


\section{UCL sensing under E-chem assistance}

UCL sensing of $\mathrm{Cu}^{2+}$ ions with the CFC-UCNP probe was accessed by monitoring the $615 \mathrm{~nm}$ emission at $0.3 \mathrm{~V}$ (Fig. 3c). A good linearity was obtained from the double natural logarithm of the SV equation (Fig. 3d) while concave downward curves were observed in either the SV or the modified SV plots (Fig. S9b and $\mathrm{d} \dagger$ ). This may indicate the involvement of reduced heterogeneity or additional mechanisms in the assays. Based on the enhanced E-chem signals with increasing $\left[\mathrm{Cu}^{2+}\right]$ (Fig. 4c), it is speculated that more analyte ions are adsorbed on the CFC-UCNP probe at $0.3 \mathrm{~V}$ and facilitate UCL deactivation. This E-chem-assisted accumulation effect can last for a period of time as revealed by the steady decrease in the UCL of the composite probe over time at fixed $\left[\mathrm{Cu}^{2+}\right]$ (Fig. S13 $\dagger$ ). By comparing the relative emission intensity in the time-lapse experiments, higher $\left[\mathrm{Cu}^{2+}\right]$ displayed greater quenching rate. This is ascribed to a larger $\left[\mathrm{Cu}^{+}\right]$gradient between the bulk solution and the CFC-UCNP probe, at which $\mathrm{Cu}^{+}$ions are consumed via oxidation rapidly. As a result, such an improved diffusion behavior can lead to better accessibility and accumulation of metal ion quenchers to the core@shell UCNPs inside the cloth pores. This accounts for the reduced heterogeneity and more efficient UCL quenching compared to the detection assays at $0 \mathrm{~V}$.

The quenching mechanism was investigated by analyzing the decay behavior of the UCL at $615 \mathrm{~nm}$. The lifetimes were gradually shortened from 4.90 to $4.13 \mathrm{~ms}$ for $0-50 \mathrm{ppm} \mathrm{Cu}^{2+}$ ions at $0.3 \mathrm{~V}$; subsequently, it was slightly increased at high $\left[\mathrm{Cu}^{2+}\right]$ (Fig. S14†). In contrast, the detection at $0 \mathrm{~V}$ could only result in a small lifetime shift of $0.13 \mathrm{~ms}$ at low $\left[\mathrm{Cu}^{2+}\right]$ and a drastic recovery of the lifetime occurred at higher $\left[\mathrm{Cu}^{2+}\right]$ (Fig. S15 $\dagger$ ). Lifetime shifts indicate that dynamic quenching processes are largely responsible for the detections, while the lifetime recoveries at high $\left[\mathrm{Cu}^{2+}\right]$ are ascribed to the increasing significance of the static quenching factor. ${ }^{19,20}$ The findings are in agreement with the SV analysis as discussed. In view of a small spectral overlap of the metal ion absorbance and $615 \mathrm{~nm}$ UCL, radiative processes such as LRET and the inner filter effect less likely dominate the UCL deactivation. In other words, the greater the collisional probability of analyte ions with the core@shell UCNPs for electron transfer, the higher the participation of a dynamic quenching mechanism in the metal ion sensing. Therefore, the large lifetime change observed in Echem-assisted sensing suggests that oxidation of $\mathrm{Cu}^{+}$ions promotes the dynamic quenching factor, likely by improving the diffusion behavior and accumulation of the analyte ions onto composite probes. Such a shortened interaction distance with the core@shell UCNPs results in more efficient UCL deactivation. In addition, more concentrated $\left[\mathrm{Cu}^{2+}\right]$ can reduce collisional events with the UCL probes, particularly in $0 \mathrm{~V}$ assays whose static quenching factor becomes important. It is noted that the complicated quenching mechanisms behind this Echem-assisted optical sensing scheme are yet to be well understood and other possible routes should not be excluded. For instance, the voltage-triggered crystal field changes in $\mathrm{Cu}^{+}$, $\mathrm{Cu}^{2+}$ and $\mathrm{Eu}^{3+}$ ions may prompt the electron transfer and nonradiative relaxation processes to give greater optical responses.
This sensing strategy offered higher stability and a much more outstanding LOD at $82 \mathrm{ppb}$ for 0-200 $\mathrm{ppm} \mathrm{Cu}^{2+}$ ions, an about 300-fold enhancement in sensitivity compared to the detection at $0 \mathrm{~V}$. It displayed comparable sensitivity and a wider working range compared to some reported UCNPs functionalized with $\mathrm{Cu}^{2+}$-chelating molecules. ${ }^{14-16}$ Hence, the E-chem technique can help establish a versatile, simple, rapid and sensitive UCL sensor. Apart from being developed as an optical sensor, the CFC-UCNP probe is also promising for UCL/E-chem dual modal sensing because the sensitivity of the E-chem sensing mode is comparable to the UCL sensing at $0.3 \mathrm{~V}$.

\section{Selectivity of the CFC-UCNP probe for $\mathrm{Cu}^{2+}$ ion sensing}

Selectivity is known to be another figure of merit of a sensor; therefore UCL of the CFC-UCNP probe was examined for some non-specific cations including $\mathrm{Zn}^{2+}, \mathrm{Ni}^{2+}, \mathrm{Pb}^{2+}$ and so on. As shown in Fig. S16, $\uparrow$ the optical responses were rather sensitive to most of the tested non-specific cations at $0 \mathrm{~V}$. The inferior selectivity is attributed to the lack of $\mathrm{Cu}^{2+}$-responsive molecules on the nanophosphors and the efficient electron transfer to the transition metal ions leads to observable UCL quenching effects. ${ }^{20}$ In particular, $\mathrm{Ni}^{2+}$ and $\mathrm{Cr}^{3+}$ ions exhibited relatively

(a)
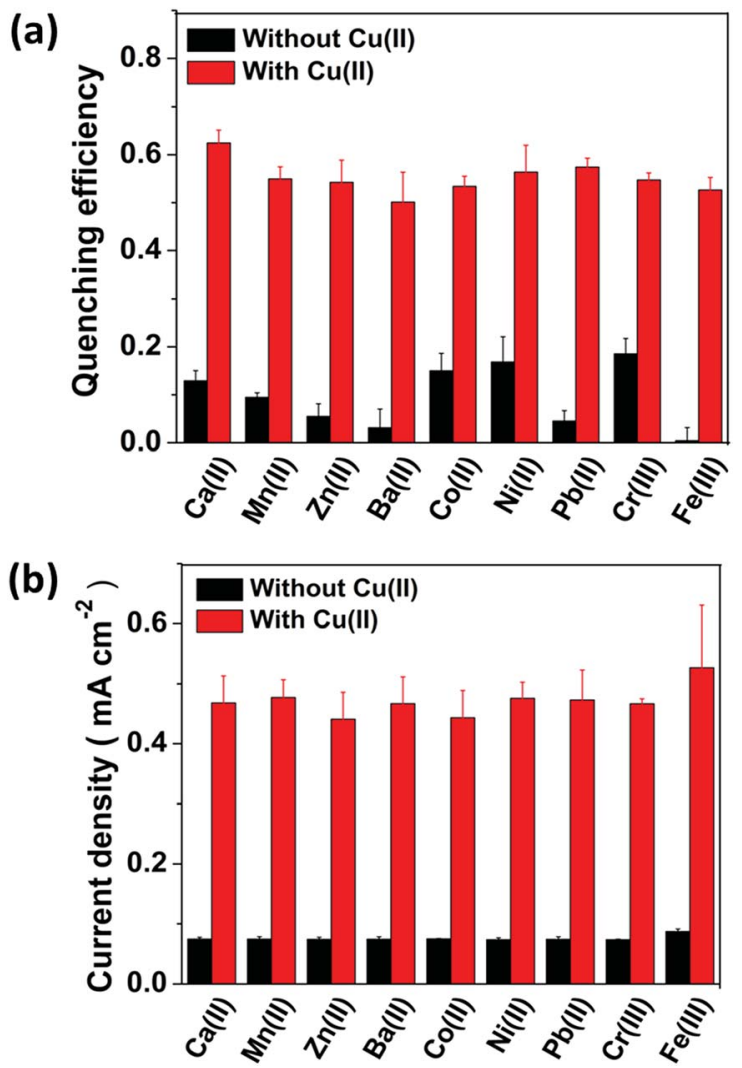

Fig. 5 (a) The optical responses and (b) the E-chem responses of the CFC-UCNP probe at $0.3 \mathrm{~V}$ for sensing various non-specific cations. Black bars correspond to the single-ion system while red bars correspond to the co-existing non-specific cation/ $\mathrm{Cu}^{2+}$ ion system. All error bars were obtained from three separated experiments $\left(\left[\mathrm{Cu}^{2+}\right]=\right.$ $315 \mu \mathrm{M},\left[\mathrm{Ba}^{2+} / \mathrm{Ni}^{2+} / \mathrm{Pb}^{2+} / \mathrm{Co}^{2+} / \mathrm{Cr}^{3+}\right]=25 \mu \mathrm{M}$ and $\left[\mathrm{Ca}^{2+} / \mathrm{Mn}^{2+} / \mathrm{Zn}^{2+} /\right.$ $\left.\left.\mathrm{Fe}^{3+}\right]=500 \mu \mathrm{M}\right)$. 
better quenching capability among the hazardous cations which are at low concentrations. The observation is likely because of their spectral overlap with UCL from the probe as an additional quenching factor (Fig. S7b $\dagger$ ). By contrast, the selectivity for $\mathrm{Cu}^{2+}$ ions was significantly enhanced at $0.3 \mathrm{~V}$ (Fig. 5a). The quenching effects of the non-specific cations were largely reduced at $0.3 \mathrm{~V}$ while the quenching efficiency was high due to $\mathrm{Cu}^{2+}$ ions present in the co-existing systems. This improvement can confirm the specific accumulation of analyte ions on the probe by the E-chem reaction. To further verify the specific oxidation of $\mathrm{Cu}^{+}$ions on the CFC-UCNP probe, its selectivity was studied based on E-chem signals. The currents across the CFCUCNP probe were drastically increased after adding $\mathrm{CuSO}_{4}$ (aq.) to any of the non-specific cations (Fig. 5b). Therefore, $\mathrm{Cu}^{+}$ions are the most responsive to the applied voltage of $0.3 \mathrm{~V}$ and are specifically adsorbed onto the composite probe resulting in a remarkable improvement in its optical sensing performance.

\section{Conclusions}

In conclusion, a composite probe was constructed by the use of CFC incorporated with core@shell UCNPs for $\mathrm{Cu}^{2+}$ ion sensing. An E-chem technique was introduced for the first time for the UCL probe, which demonstrated a significant improvement in its sensitivity and selectivity due to specific accumulation of analyte ions on the probe. The LOD of the sensor was drastically improved from $25.8 \mathrm{ppm}$ to $82 \mathrm{ppb}$ under a small potential, which is lower than the tolerance levels suggested by WHO and USEPA. Our work suggests that the proposed flexible composite probe is a promising sensor for on-site monitoring of contaminated drinking water with high sensitivity and selectivity. The sensing scheme can be potentially extended to sensing other heavy metal ions by choosing suitable applied voltages and electrolytes.

\section{Conflicts of interest}

There are no conflicts to declare.

\section{Acknowledgements}

The research was supported by grants from the Research Grants Council (RGC) of Hong Kong (RGC GRF No. PolyU 153036/14P) and PolyU Project (4-BCCA).

\section{Notes and references}

1 J. A. Cotruvo Jr, A. T. Aron, K. M. Ramos-Torres and C. J. Chang, Chem. Soc. Rev., 2015, 44, 4400-4414.

2 S. G. Kaler, Nat. Rev. Neurol., 2011, 7, 15-29.

$3 \mathrm{X} . \mathrm{Pu}, \mathrm{Z}$. Jiang, B. $\mathrm{Hu}$ and H. Wang, J. Anal. At. Spectrom., 2004, 19, 984-989.

4 X. Duan, R. L. McLaughlin, I. D. Brindle and A. Conn, J. Anal. At. Spectrom., 2002, 17, 227-231.

5 K. C. Teo and J. Chen, Analyst, 2001, 126, 534-537.
6 H. Dong, S. R. Du, X. Y. Zheng, G. M. Lyu, L. D. Sun, L. D. Li, P. Z. Zhang, C. Zhang and C. H. Yan, Chem. Rev., 2015, 115, 10725-10815.

7 P. Huang, W. Zheng, S. Zhou, D. Tu, Z. Chen, H. Zhu, R. Li, E. Ma, M. Huang and X. Chen, Angew. Chem., Int. Ed., 2014, 53, 1252-1257.

8 J. Peng, W. Xu, C. L. Teoh, S. Han, B. Kim, A. Samanta, J. C. Er, L. Wang, L. Yuan, X. Liu and Y.-T. Chang, J. Am. Chem. Soc., 2015, 137, 2336-2342.

9 Y. Liu, D. Tu, W. Zheng, L. Lu, W. You, S. Zhou, P. Huang, R. Li and X. Chen, Nano Res., 2018, 11, 3164-3174.

10 M. K. Tsang, G. Bai and J. Hao, Chem. Soc. Rev., 2015, 44, 1585-1607.

11 Z. Yi, X. Li, Z. Xue, X. Liang, W. Lu, H. Peng, H. Liu, S. Zeng and J. Hao, Adv. Funct. Mater., 2015, 25, 7119-7129.

12 M.-K. Tsang, Y.-T. Wong and J. Hao, Small Methods, 2018, 2, 1700265.

13 X. Lei, R. Li, D. Tu, X. Shang, Y. Liu, W. You, C. Sun, F. Zhang and X. Chen, Chem. Sci., 2018, 9, 4682-4688.

14 J. Zhang, B. Li, L. Zhang and H. Jiang, Chem. Commun., 2012, 48, 4860-4862.

15 C. Li, J. Liu, S. Alonso, F. Li and Y. Zhang, Nanoscale, 2012, 4, 6065-6071.

16 Z. Cui, W. Bu, W. Fan, J. Zhang, D. Ni, Y. Liu, J. Wang, J. Liu, Z. Yao and J. Shi, Biomaterials, 2016, 104, 158-167.

17 Q. Liu, J. Peng, L. Sun and F. Li, ACS Nano, 2011, 5, 80408048.

18 S. Xu, S. Xu, Y. Zhu, W. Xu, P. Zhou, C. Zhou, B. Dong and H. Song, Nanoscale, 2014, 6, 12573-12579.

19 T. Liang, Z. Li, D. Song, L. Shen, Q. Zhuang and Z. Liu, Anal. Chem., 2016, 88, 9989-9995.

20 S. M. Saleh, R. Ali and O. S. Wolfbeis, Chem.-Eur. J., 2011, 17, 14611-14617.

21 B. C. Barja and P. F. Aramendia, Photochem. Photobiol. Sci., 2008, 7, 1391-1399.

22 F. Wang, Y. Han, C. S. Lim, Y. Lu, J. Wang, J. Xu, H. Chen, C. Zhang, M. Hong and X. Liu, Nature, 2010, 463, 1061-1065.

23 F. Wang, R. Deng, J. Wang, Q. Wang, Y. Han, H. Zhu, X. Chen and X. Liu, Nat. Mater., 2011, 10, 968-973.

24 J. Qi, J. Chen, G. Li, S. Li, Y. Gao and Z. Tang, Energy Environ. Sci., 2012, 5, 8937-8941.

25 L. He, Y. Liu, J. Liu, Y. Xiong, J. Zheng, Y. Liu and Z. Tang, Angew. Chem., Int. Ed., 2013, 52, 3741-3745.

26 M.-K. Tsang, W. Ye, G. Wang, J. Li, M. Yang and J. Hao, ACS Nano, 2016, 10, 598-605.

27 Y. Li, J. Tang, L. He, Y. Liu, Y. Liu, C. Chen and Z. Tang, Adv. Mater., 2015, 27, 4075-4080.

28 G. Bai, M.-K. Tsang and J. Hao, Adv. Funct. Mater., 2016, 26, 6330-6350.

29 W. Yantasee, Y. Lin, T. S. Zemanian and G. E. Fryxell, Analyst, 2003, 128, 467-472.

30 Y. Liu, N. Fu, G. Zhang, M. Xu, W. Lu, L. Zhou and H. Huang, Adv. Funct. Mater., 2017, 27, 1605307.

31 Z. Xu and C. Gao, Mater. Today, 2015, 18, 480-492.

32 WHO, Guidelines for drinking-water quality: fourth edition incorporating the first addendum, World Health Organization, Geneva, 2017. 
33 USEPA, National Primary Drinking Water Regulations, United States Environmental Protection Agency, 2009.

34 F. Wang, R. Deng and X. Liu, Nat. Protoc., 2014, 9, 16341644.

35 N. Bogdan, F. Vetrone, G. A. Ozin and J. A. Capobianco, Nano Lett., 2011, 11, 835-840.

36 Z. Wu, C. U. Pittman and S. D. Gardner, Carbon, 1995, 33, 597-605.
37 W. Shao, G. Pattanaik and G. Zangari, J. Electrochem. Soc., 2007, 154, D201-D207.

38 S. Basak, P. S. Zacharias and K. Rajeshwar, J. Electroanal. Chem. Interfacial Electrochem., 1991, 319, 111-123.

39 J. Peng, J. Li, W. Xu, L. Wang, D. Su, C. L. Teoh and Y.-T. Chang, Anal. Chem., 2018, 90, 1628-1634.

40 D. Tu, Y. Liu, H. Zhu, R. Li, L. Liu and X. Chen, Angew. Chem., Int. Ed., 2013, 52, 1128-1133. 